\title{
PLANTAR PRESSURE MEASUREMENTS AND THE PREVENTION OF ULCERATION IN THE DIABETIC FOOT
}

\author{
T. DUCKWORTH, A. J. M. BOULTON, R. P. BETTS, C. I. FRANKS, J. D. WARD
}

From the Royal Hallamshire Hospital, Sheffield

\begin{abstract}
Static and dynamic measurements of foot pressure have been carried out on three groups of subjects: diabetic patients with neuropathy (with and without a history of ulceration), diabetic patients with no neuropathy, and normal subjects as controls. In many cases both techniques of measurement detected areas of abnormally high pressure under the foot, but in some cases a particularly high-pressure spot was detected on only one of the tests and sometimes both methods were needed to reveal all the areas of the foot which might be considered to be at risk. The dynamic measurements tended to show multiple areas of high pressure better than the static measurements. Our results indicate the importance of making both types of measurement when seeking to devise suitable means of protecting the foot from ulceration.
\end{abstract}

It has been estimated that complications affecting the foot now account for about $20 \%$ of all admissions of diabetics to hospital (Bessman 1982). It was recognised long ago that ulceration could be produced by deformity of the foot causing changes in the pattern of weightbearing (Treves 1884), and this is particularly the case when the sensibility is disturbed. It is possible that some, at least, of these problems could be avoided if those patients who are particularly at risk could be identified, so that appropriate preventive measures, such as modification of footwear, could be taken in good time. A previous publication (Boulton et al. 1983) described a number of predictive factors which might be helpful in detecting those feet which are at risk. The investigations carried out in that study included motor conduction velocity in the median and peroneal nerves, vibration perception threshold in the great toes, the Valsalva response, skin resistance, and the ankle pressure index. Of these investigations the vibration perception threshold correlated most significantly with the occurrence of foot ulceration.

In a series of 41 patients with diabetic neuropathy (Boulton et al. 1983) $51 \%$ of the feet, when measured by a pedobarographic technique, had abnormally high pressures under the metatarsals, compared with $17 \%$ of a similar series of diabetic controls and only $7 \%$ of a series of non-diabetic subjects. All those feet which had at some time developed ulceration had abnormally high pressures at the ulcer sites.

T. Duckworth, FRCS, Professor of Orthopaedic Surgery A. J. M. Boulton, MRCP, Senior Lecturer

R. P. Betts, M Med Sci, PhD, CEng, MIEE, Principal Physicist

C. I. Franks, PhD, CEng, MIEE, Principal Physicist

J. D. Ward, MD, FRCP, Consultant Physician

Royal Hallamshire Hospital, Sheffield S10 2JF, England.

Requests for reprints should be sent to Professor T. Duckworth.

(c) 1985 British Editorial Society of Bone and Joint Surgery $0301-620 \mathrm{X} / 85 / 1034 \$ 2.00$
It was concluded that simple bedside investigations, such as measurement of the vibration perception threshold alone, might be useful in identifying those patients at risk of foot ulceration, and that pressure studies might then be used to identify the specific areas under the foot which were prone to ulceration.

The present paper describes an investigation into the use of static and dynamic studies of foot pressure in this predictive role.

\section{PATIENTS AND METHODS}

Eighty-two diabetic and 41 non-diabetic subjects were investigated. They were divided into three groups, the criteria for this grouping being described more fully in a previous publication (Boulton et al. 1983). Group A consisted of 41 patients with diabetic neuropathy; 13 of these (Group Al) had a history of neuropathic foot ulceration involving 22 feet, while the remaining 28 patients (Group A2) had no history of foot ulceration. Group B consisted of 41 diabetic patients, who were matched with Group A for age, sex, duration and type of diabetes; none of these patients had any evidence of diabetic neuropathy, peripheral vascular disease, or foot ulceration. Group A and Group B each had 20 patients who were not dependent on insulin. Group $C$ consisted of 41 healthy non-diabetic subjects matched with Groups $A$ and $B$ for age and sex; no subject in this group had glycosuria or a family history of diabetes.

In each group there were 29 men and 12 women, with a mean age of 52 years.

The measurement of the distribution of pressure under the foot uses an optical method, details of which have been fully described elsewhere (Duckworth $e t$ al. 1982). Essentially, the subject stands or walks on a glass plate which is illuminated at its edges by strip lights and is covered by a sheet of soft white plastic. At the points where the plastic sheet is pressed into contact with the 
glass plate by the foot, light which is normally contained within the glass by total internal reflection escapes from the glass and is scattered by the plastic sheet, producing an image of the foot which can be seen from below. The greater the applied pressure, the brighter the image at that point. The grey image of the sole is detected by a monochrome television camera and the pressure at any point under the foot can be determined automatically by measuring the intensity of the image at that point; this is represented as a voltage level in the output from the camera. The patient may stand on the plate to produce a static pressure profile, or may walk across the plate, causing the image to change as the various parts of the foot make contact. In order to analyse the changing image, the analogue information contained in every alternate frame from the television camera signal is first converted to digital form. The digitised information is stored in the microcomputer memory and may be pressure through the footstep for each area of interest is automatically calculated and all the pressure/time curves are then displayed together on the monitor. The raw and analysed data are recorded on a floppy disc system and plotted in a form suitable for the patients' records. Figures 3 and 5 are typical plotter outputs for dynamic studies. On the left there are 10 sample frames from the total number recorded, each showing a series of isopressure contour lines for the footprint at that moment. On the right is a composite frame produced by combining all the recorded frames. Below this, selected areas of interest are outlined. Below this are the peakpressure/time curves for the selected areas of interest. The iso-pressure contour lines, the areas of interest and the peak-pressure/time graphs are normally produced in colour-coded form, but for the purpose of photographic illustration in this paper they are shown in black only and the graphs have been numbered by hand.

Table I. Results of the foot pressure studies for the four groups indicating the ability to detect abnormal feet using static and/or dynamic methods

\begin{tabular}{|c|c|c|c|c|c|c|}
\hline \multirow[b]{2}{*}{ Group } & \multirow[b]{2}{*}{$\begin{array}{l}\text { Total number } \\
\text { of feet }\end{array}$} & \multirow[b]{2}{*}{$\begin{array}{l}\text { Abnormal on } \\
\text { dynamic test }\end{array}$} & \multirow[b]{2}{*}{$\begin{array}{l}\text { Abnormal on } \\
\text { static test }\end{array}$} & \multicolumn{2}{|c|}{ "Missed" abnormalities } & \multirow[b]{2}{*}{$\begin{array}{l}\text { Abnormal on either } \\
\text { dynamic or static } \\
\text { test }\end{array}$} \\
\hline & & & & $\begin{array}{l}\text { Normal on dynamic } \\
\text { but abnormal on } \\
\text { static tests }\end{array}$ & $\begin{array}{l}\text { Normal on static } \\
\text { but abnormal on } \\
\text { dynamic tests }\end{array}$ & \\
\hline $\begin{array}{l}\text { A1: neuropathy + } \\
\text { ulcers }\end{array}$ & 22 & 20 & 15 & 1 & 6 & 21 \\
\hline $\begin{array}{l}\text { A2: neuropathy } \\
\text { no ulcers }\end{array}$ & 56 & 19 & 14 & 7 & 12 & 26 \\
\hline B: no neuropathy & 81 & 23 & 22 & 7 & 7 & 30 \\
\hline C: controls & 82 & 10 & 11 & 5 & 3 & 15 \\
\hline
\end{tabular}

Static results from two patients in Group B and 12 in Group C were not available. One such patient from each of these two groups is included in the table on the basis of having an abnormal dynamic result, although no static result was available

continuously displayed on a colour television monitor as an image of the foot with 16 colour levels, each corresponding to a given plantar pressure (Franks, Betts and Duckworth 1983).

The system is currently calibrated by the use of four vertical-force transducers, mounted one under each corner of the glass pressure plate. For static measurements calibration is achieved by comparison of the sum of the force transducer outputs with body weight. During dynamic studies a frame by frame calibration is performed by comparison of the sum of the force transducer outputs with the integrated pressure (light) output.

In the dynamic studies, information from the frames which go to make up a complete footstep can be combined to form a composite pressure image of the whole foot; areas of interest may be defined on this image by the use of a simple "joystick" control. The usual areas of interest selected are the heel, the five metatarsal heads, the great toe and the other toes. The variation of peak

\section{RESULTS}

Figure 1 shows the results of static measurements for the four groups as a scatter diagram, the horizontal line at $1.75 \mathrm{~kg} \cdot \mathrm{cm}^{-2}$ representing the threshold of normality. These results are of the peak pressure recorded at any point under the forefoot. Table I summarises these results, but two from Group B and 12 from Group C were not available.

Figure 2 shows the results of dynamic measurements for the four groups as a scatter diagram. Again, the points recorded on the diagram show the peak pressure reached at any point under the forefoot and, in this case, at any time during the course of a single footstep. The horizontal line at $10 \mathrm{~kg} \cdot \mathrm{cm}^{-2}$ represents the threshold of normality. All the patients represented by the points above this line had peak pressures under the foot greater than this threshold, and the upper part of the diagram has been used to illustrate the length of time that the pressure remained above this threshold level during one footstep. Table I summarises these results. 


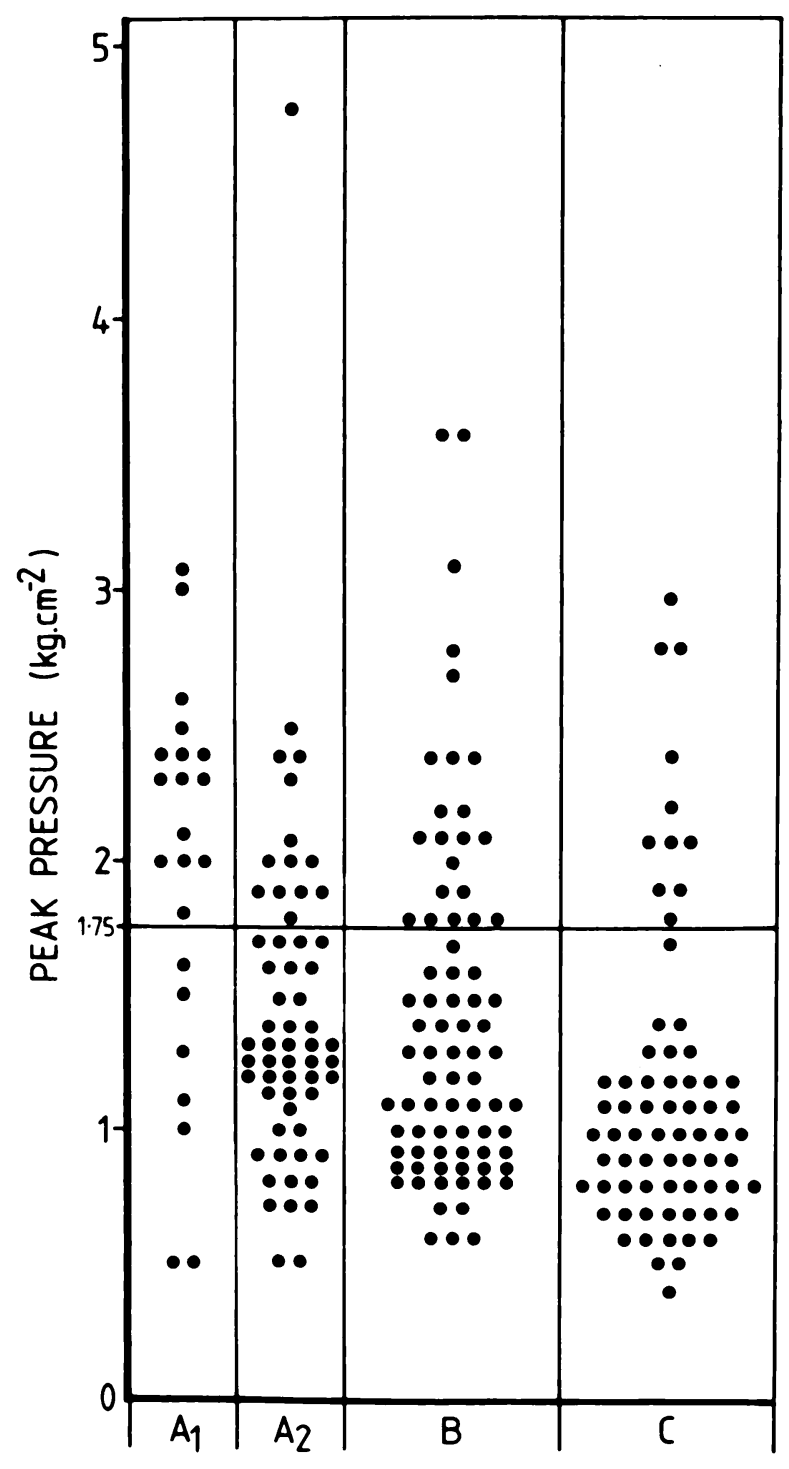

Fig. 1
Figure 1-Scatter diagram showing the peak pressures recorded in the three groups from static measurements.

Figure 2-Scatter diagram showing the peak pressures recorded in the three groups from dynamic measurements. Above $10 \mathrm{~kg} \mathrm{~cm}{ }^{-2}$ the results represent the length of time during which the pressure exceeds this level.

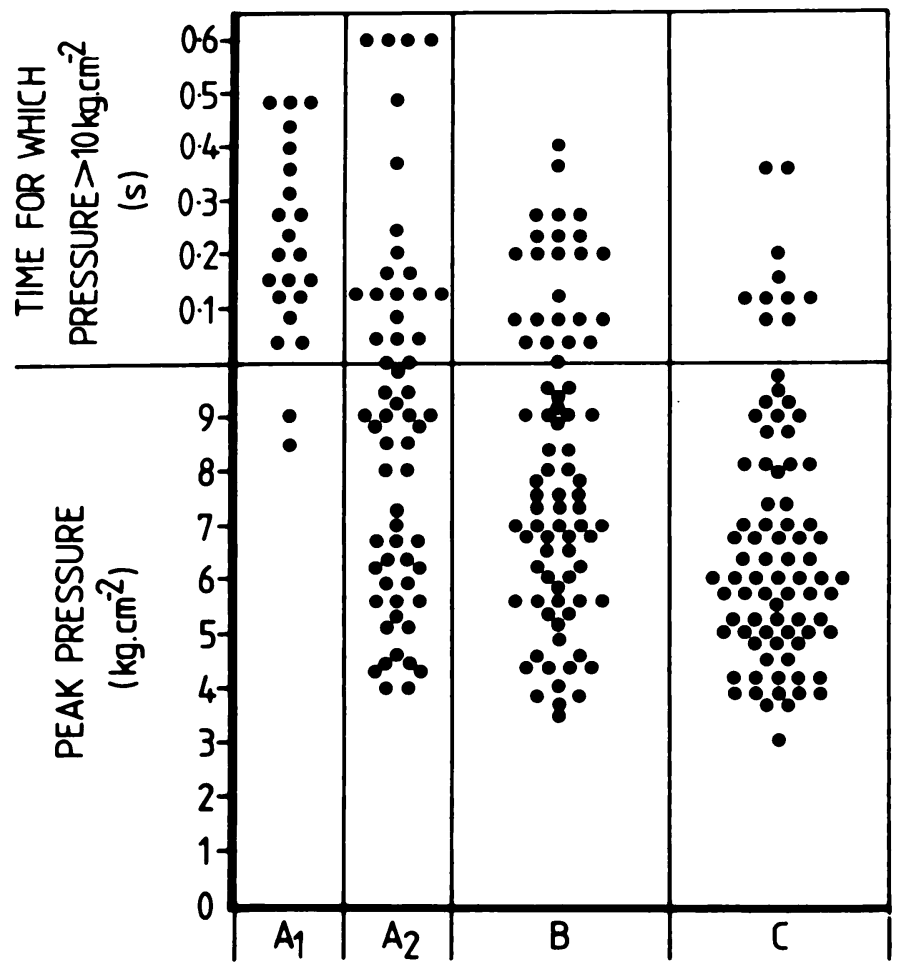

Fig. 2 
Table I also shows a comparison between the two methods of pressure recording for the four groups, indicating the ability to detect abnormal feet using static and/or dynamic methods.

\section{ILLUSTRATIVE CASE REPORTS}

Case 1. A 45-year-old white male police officer, weight $91 \mathrm{~kg}$. had been an insulin-dependent diabetic for 11 years, with diabetic neuropathy for two years. There was no history of ulceration of the feet. At the time of examination he had no symptoms referable to the feet, no deformities and no callosities. There was no obvious prominence in the sole of the foot, although it was noted that the second metatarsal was slightly longer than usual. There was no detectable sensory disturbance on testing with cotton-wool and pin-prick but the vibration perception threshold was 25 units (the normal range is 2 to 10 units). The circulation appeared normal.

Dynamic pressure studies (Fig. 3) showed that the pressure under the second metatarsal head of the right foot reached an abnormally high level. The static studies (Fig. 4) also showed an abnormally high level of pressure under the right foot, but in this case under the fifth metatarsal head.

Case 2. A 45-year-old white housewife, weight $72 \mathrm{~kg}$, had a 30-year history of insulin-dependent diabetes and symptoms of neuropathy for

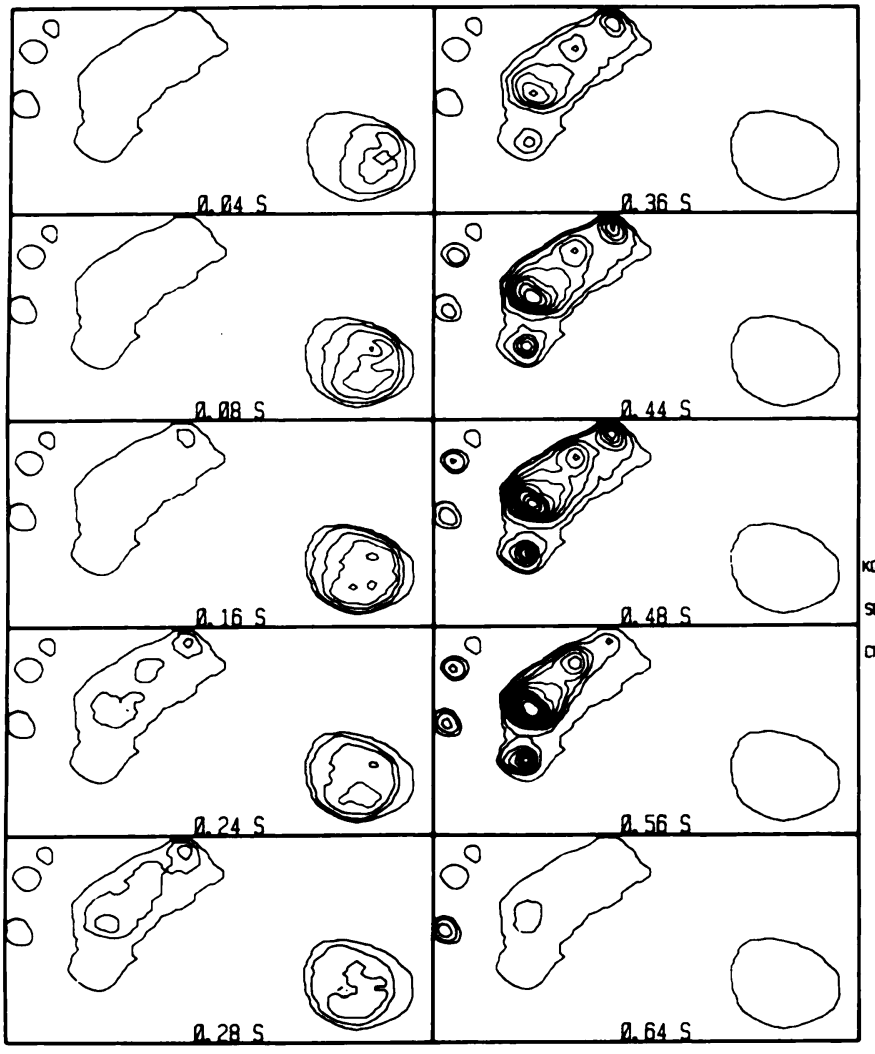

Fig. 3

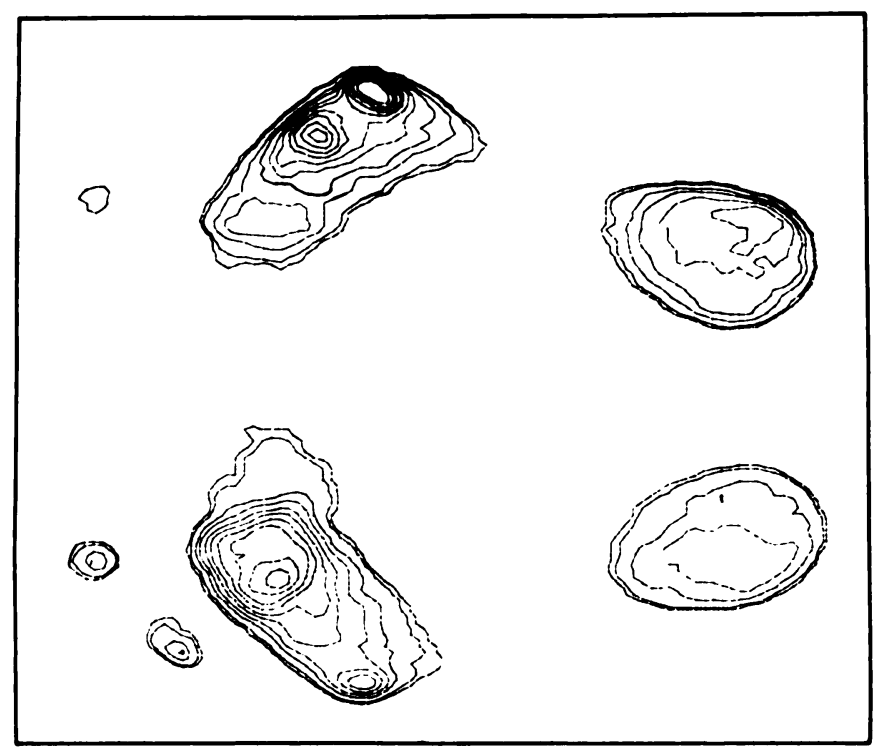

Fig. 4

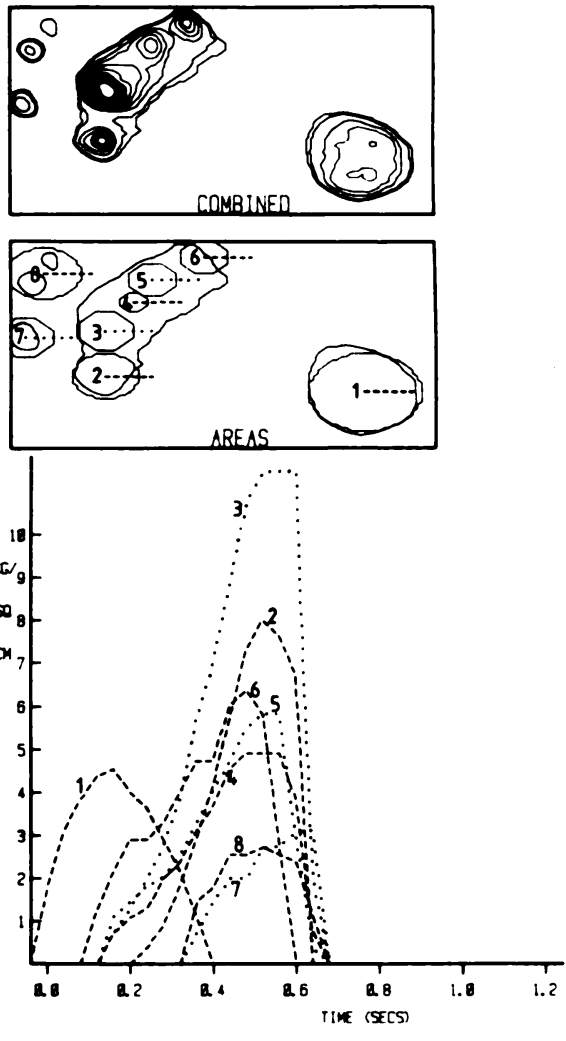

Case 1, a diabetic patient with neuropathy but no history of ulceration (Group A2).

Figure 3-Dynamic pressure measurements in the right foot: pressure under the second metatarsal head exceeded the normal range.

Figure 4-Static measurements in both feet: pressure under the fifth metatarsal head in the right foot has exceeded the normal range reaching a value of $2.3 \mathrm{~kg} \cdot \mathrm{cm}^{-2}$. 
four years. There was no history of ulceration of the feet. At the time of examination she complained of a burning sensation in both lower legs and feet. The feet were undeformed with no obvious prominent areas in the sole. There was a slight non-tender callosity under the second metatarsal head on the right foot. There was no detectable sensory loss to pin-prick or cotton-wool, but the vibration perception threshold was 27 units. The circulation appeared normal, although the ankle pulses were difficult to palpate on the right side.

Dynamic pressure studies (Fig. 5) showed that the peak pressure under the first metatarsal head of the right foot reached an abnormally high level, which was not reflected in the static pressure measurement
(Fig. 6) where all pressure levels were normal. Figure 6 shows a tendency for the greatest loading to be on the lateral border during standing.

\section{DISCUSSION}

It is hardly possible, and probably not necessary, to carry out pedobarographic screening of all diabetic patients. If those patients who are particularly at risk can be identified, for example by means of the simple clinical test of vibration perception threshold, then pressure

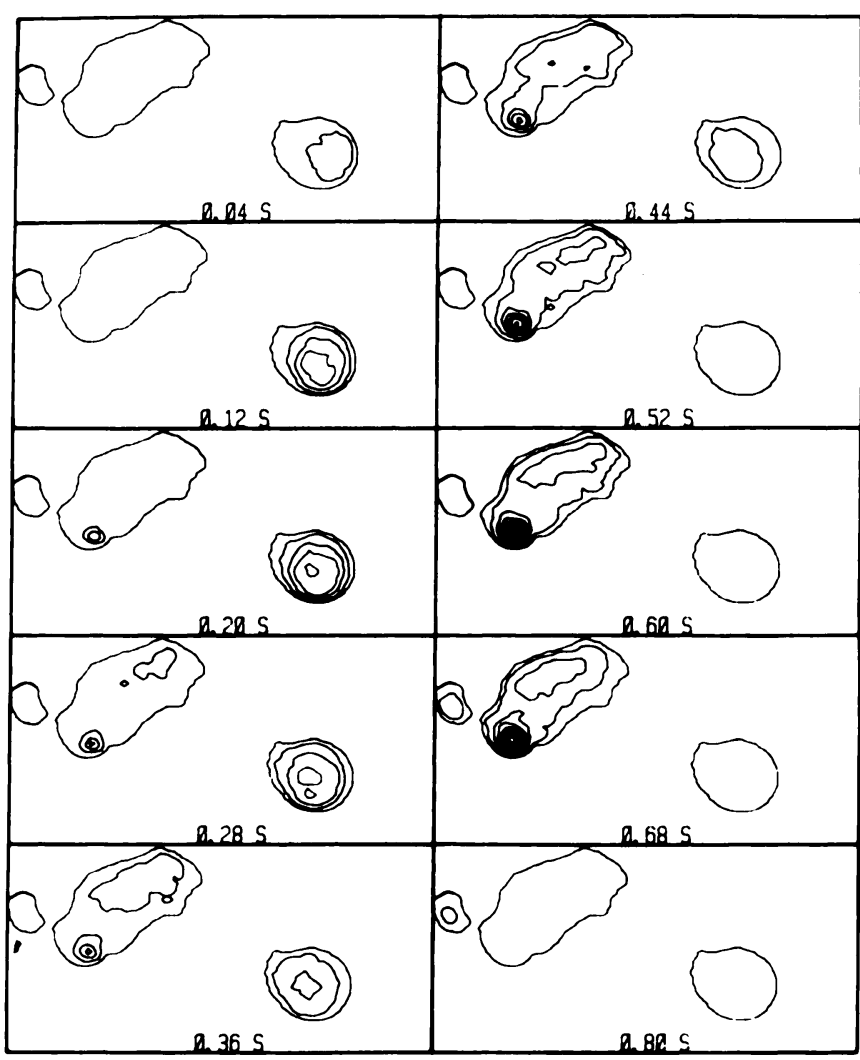

Fig. 5
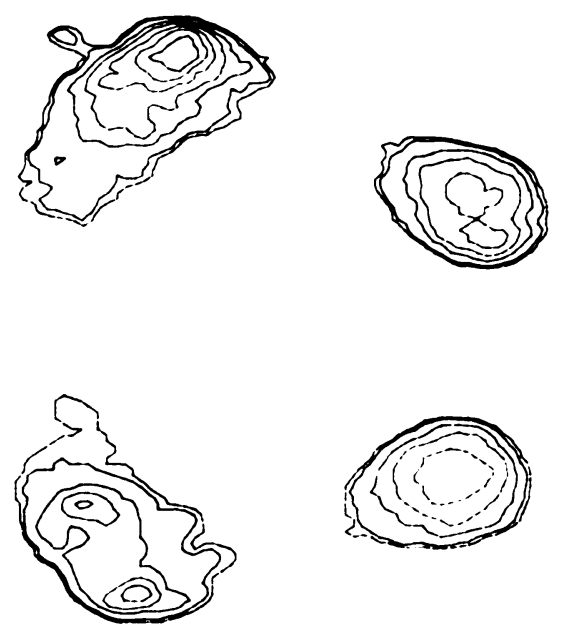
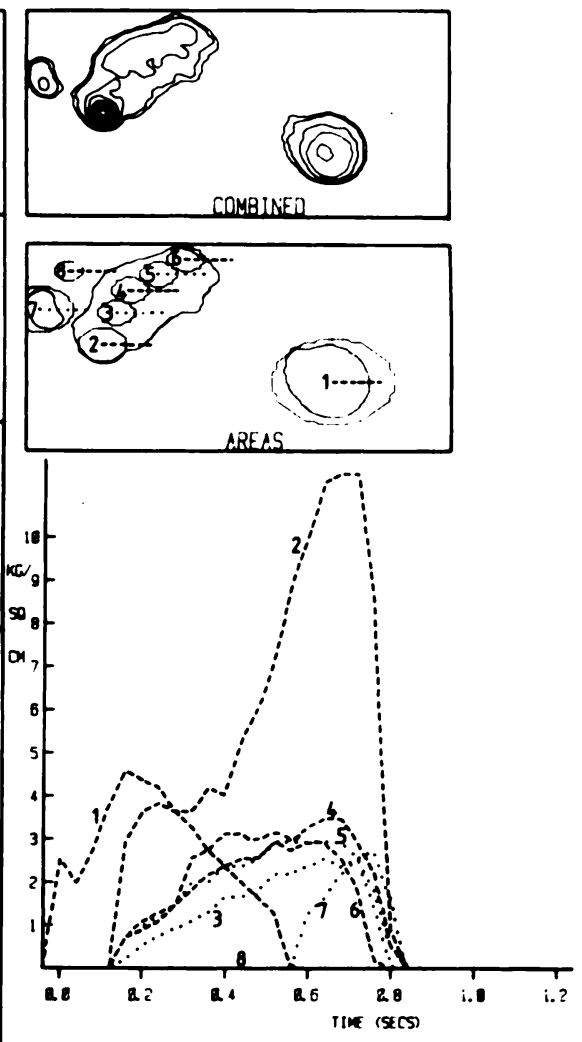

Case 2, also from Group A2.

Figure 5-Dynamic pressure measurements in the right foot: pressure under the first metatarsal head has exceeded the normal range.

Figure 6-Static measurements in both feet: the peak of pressure (right foot) is under the fifth metatarsal head but is within normal limits. 
measurements may be useful in identifying still further the feet which are specially vulnerable and, in particular, which part of the foot is likely to develop ulceration. It has previously been shown that abnormally high pressures are more common in patients with diabetic neuropathy and that almost all patients with a history of ulceration show high-pressure areas which correlate well with the site of previous ulceration. The present paper is an attempt to refine the pedobarographic analysis, and to define which type of measurement is likely to give the most useful information. The equipment is sophisticated so that its use can only be justified if it can be shown to have advantages over simple clinical judgement. Similarly, the more complicated technique of dynamic pressure measurement could only be justified if it were proved to have a significant advantage over the less-complicated measurement of static pressures.

The results for the static pressure measurements have been tabulated on the basis of a threshold level of abnormality of $1.75 \mathrm{~kg} \cdot \mathrm{cm}^{-2}$. The justification for this lies in previously published results in the form of distribution curves for normal patients (Betts et al. 1980a). This threshold level may indeed slightly underestimate the number of patients who should be considered abnormal, because the distribution curves in Betts' published series were somewhat skewed towards the upper levels, suggesting that some of the "normal" individuals were in fact not normal, although all were symptom-free at the time of testing. The threshold level of $10 \mathrm{~kg} \cdot \mathrm{cm}^{-2}$ for the dynamic measurements has similarly been chosen on the basis of previously published results (Betts et al. 1980b).

Using these thresholds, in Group Al, that is those patients with neuropathy and a history of ulceration, 20 of the total of 22 feet were found to have an abnormally high pressure level on the dynamic measurements; of these 20 , only 14 were found to be abnormal on the static measurements, ie the static method "missed" six abnormal feet. On the other hand, one foot was found to be abnormal on the static measurement but normal on the dynamic. Similarly, in Group A2 the static measurement "missed" 12 of the 19 feet indicated to be abnormal dynamically and the dynamic "missed" 7 of the 14 feet detected statically. Reference to Table I shows that in every group there were a number of feet which were abnormal on both the static and the dynamic measurements but also some feet which were only detected as abnormal by one of the two techniques of measurement.

It is noticeable that there were some subjects in Group $\mathrm{C}$ who had abnormally high pressures on either or both of the measurement techniques. Patients were allocated to Group $C$ if they denied having any symptoms related to their feet and if they had never had any operative procedure on the feet. Subsequent examination of the Group C subjects showed a number to have marked callosities and these showed as abnormal on the scatter diagrams. If these patients were excluded from the "control" group, the contrast between this group and Groups A and B would of course be more marked.

No attempt was made in this study to correlate the results of pedobarographic measurement with clinical judgement of "high spots", although it was frequently noted that high-pressure points detected by the system were not obvious on clinical examination. This was the case in the two patients illustrated in the case reports. Even when there was an obvious prominence, no assessment of the level of pressure which might be reached could be made purely on clinical grounds.

Inspection of the pressure contour maps of the foot shows that the high-pressure points in the group with a previous history of diabetic ulceration correlated with the site of previous ulceration. It may perhaps, therefore, be inferred that similar high-pressure areas in the feet of those patients with neuropathy but no history of ulceration are likely to represent the sites at which ulceration is likely to occur in the future.

In most patients, the site of abnormally high pressure was under the metatarsal heads. The dynamic measurements sometimes showed other metatarsal heads to be at risk in addition to those which corresponded to the site of previous ulceration. When extra metatarsal heads were at risk, the dynamic measurements almost always demonstrated them, whereas the static system often failed to do so; in some cases the static system failed to demonstrate even those areas which had been the site of previous ulceration.

The reason why either one of the two techniques may fail to demonstrate high-pressure areas which are revealed by the other is not always clear. During the measurement of static pressures the patient is normally standing on both feet and may, consciously or subconsciously, off-load one foot, particularly if a high-pressure area is sensitive. Clearly, this might well be less of a problem in those patients with marked sensory loss. On the other hand, in this latter group of patients, problems of proprioception and balance may lead to asymmetrical loading whilst standing. It is also, of course, quite possible that in the walking foot, changes in shape and relative loading may occur which would not be evident in the standing position. Similarly, the fact that some highpressure areas are not picked up on the dynamic print may be due to voluntary or involuntary off-loading of a part of the foot which would otherwise be taking an abnormally high load. This off-loading could take place partly to the other foot or, more likely, within the foot. This phenomenon is certainly seen in some painful conditions of the foot when a relatively low pressure area at a painful site may be revealed as a high spot if the patient is asked to try to ignore the pain and to walk normally.

It is proposed to use the measurements made in this way to design suitable protective footwear, and preliminary results with insoles have suggested that it is possible to equalise the loads and redistribute the pressures under 
the foot (Boulton et al. 1984). Similar techniques have already been used in designing footwear (Reed 1974, 1983) but these tended to be based on either static or dynamic measurements alone. Our results would suggest that the use of either system alone could lead to dangers. For example, a static measurement may reveal a high spot under one metatarsal head and suggest that there is no increased loading under the others. It would then be logical to design an orthosis to off-load the pressure to those other heads. The dynamic measurement, on the other hand, might well show that several of these metatarsals are, in fact, already taking high loads and increasing their loading might prove critical. The patient in Case 1 illustrates this point in that the high-pressure sites were different on the static and dynamic studies.

It should be emphasised that the technique described measures the reaction at the interface between the sole of the foot and a flat surface. The shape and consistency of the sole of the shoe will, of course, modify the pressures at the interface between foot and insole. The study is therefore currently being extended to take measurements within the shoe, in the belief that this will further refine the design of protective shoes and insoles and may give some indication as to when corrective surgery should be considered.

It would appear from these findings that, in order to determine fully all the danger areas, both static and dynamic systems of measurement are required. With the system used here, both types of measurement can readily be made at the same examination.

This work was supported by the Marjorie Parsons Diabetic Research Fund. We thank Drs D. R. Cullen and F. J. Flint for permitting us to study patients under their care.

\section{REFERENCES}

Bessman AN. Foot problems in the diabetic. Compr Ther $1982: 8(1): 32-7$

Betts RP, Franks CI, Duckworth T, Burke J. Static and dynamic foot pressure measurements in clinical orthopaedics. Med Biol Eng Comput 1980a;18(5):674-84.

Betts RP, Franks CI, Duckworth T. Analysis of pressures and loads under the foot. Part 1: Quantitation of the static distribution using the PET computer. Part 2: Quantitation of the dynamic distribution. Clin Phys Physiol Meas 1980b;1:101-12, 113-24.

Boulton AJM, Franks CI, Betts RP, Duckworth T, Ward JD. Reduction of abnormal foot pressures in diabetic neuropathy using a new polymer insole material. Diabetes Care 1984;7(1):42-6.

Boulton AJM, Hardisty CA, Betts RP, et al. Dynamic foot pressure and other studies as diagnostic and management aids in diabetic neuropathy. Diabetes Care 1983:6(1):26-33.
Duckworth T, Betts RP, Franks CI, Burke J. The measurement of pressures under the foot. Foot Ankle 1982;3(3):130-41.

Franks CI, Betts RP, Duckworth T. A microprocessor-based image processing system for dynamic foot pressure studies. Med Biol Eng Comput 1983;21(5):566-72.

Reed JK Jr. Plastazote insoles, sandals and shoes-for insensitive feet. In: McDowell F, Enna CD, eds. Surgical rehabilitation in leprosy and in other peripheral disorders. Baltimore: Williams \& Wilkins, 1974:323-9.

Reed JK Jr. Footwear for the diabetic. In: Levin ME, O'Neal LW, eds The diabetic foot. 3rd edition. St Louis, Toronto, London: CV Mosby Co, 1983:360-77.

Treves F. Treatment of perforating ulcer of the foot. Lancet 1884;ii:949-51. 